\title{
Complexity in Implementing Community Drowning Reduction Programs in Southern Bangladesh: A Process Evaluation Protocol
}

\author{
Medhavi Gupta ${ }^{1, *(\mathbb{D}}$, Aminur Rahman ${ }^{2}$, Kamran ul Baset ${ }^{2}$, Rebecca Ivers ${ }^{3}$, Anthony B. Zwi ${ }^{4}$, \\ Shafkat Hossain ${ }^{2}$, Fazlur Rahman ${ }^{2}$ and Jagnoor Jagnoor ${ }^{5}$ \\ 1 The George Institute for Global Health, University of New South Wales, Level 5/1 King St, \\ Newtown, NSW 2042, Australia \\ 2 Centre for Injury Prevention and Research, Bangladesh, House 162B, Road 23, New DOHS, Mohakhali, \\ Dhaka 1206, Bangladesh; aminur@ciprb.org (A.R.); kamran@ciprb.org (K.u.B.); shafkat@ciprb.org (S.H.); \\ fazlur@ciprb.org (F.R.) \\ 3 School of Public Health and Medicine, Faculty of Medicine, UNSW Australia, Wallace Wurth Building, \\ Botany Street, Kensington, NSW 2052, Australia; rebecca.ivers@unsw.edu.au \\ 4 School of Social Sciences, Faculty of Arts and Social Sciences, UNSW Australia, Morven Brown Building, \\ Kensington, NSW 2052, Australia; a.zwi@unsw.edu.au \\ 5 The George Institute for Global Health, University of New South Wales, 311-312, Third Floor, \\ Elegance Tower, Plot No. 8, Jasola District Centre, New Delhi 110025, India; \\ jjagnoor1@georgeinstitute.org.in \\ * Correspondence: mgupta@georgeinstitute.org.au
}

Received: 29 January 2019; Accepted: 12 March 2019; Published: 18 March 2019

\begin{abstract}
Living and geographical conditions in Bangladesh expose children to a high risk of drowning. Two programs operating in the Barishal Division of Bangladesh aim to reduce drowning risk through the provision of crèches (Anchal) and swim and rescue classes (SwimSafe). Anchal provides a safe environment with early childhood education to children aged 1-5 years old, while SwimSafe teaches children aged 6-10 years old basic swimming and rescue skills. Despite evidence for their effectiveness, it is unclear under which conditions these programs best operate. This protocol describes a project that seeks to conduct a process evaluation and gender analysis to identify implementation inefficiencies and contextual considerations for improved sustainability of the programs. A mixed- method approach using both qualitative and quantitative data will be used. Quantitative program data will be analysed to measure program utilisation, delivery and reach, while qualitative data will be collected via key informant in-depth interviews (IDIs), focus group discussions (FGDs) and observations. The process evaluation of the Anchal and SwimSafe programs provides an opportunity for implementers to identify practical strategies to improve program delivery and improve contextual adaptability of these programs. Furthermore, the findings may provide guidance to other implementers aiming to deliver community-based programs in rural lower-middle income contexts.
\end{abstract}

Keywords: drowning; process evaluation; evaluation studies; community health workers; rural population; child; education; Bangladesh; injury

\section{Introduction}

Globally, children aged 1-14 years in lower-middle-income countries (LMICs) are at the greatest risk of morbidity and mortality from drowning. This burden is particularly significant in Bangladesh, where $43 \%$ of deaths in children aged 1-4 years occur from drowning [1,2]. The rate of fatal drowning 
in Bangladesh is 122 per 100,000 children in 1-4 years old and 23 per 100,000 in children aged 5-9 years old, significantly higher than the average of 16 per 100,000 in the general population. Non-fatal drowning rates show a similar trend, with a rate of 3058 per 100,000 children in 1-4 years old children and 466 per 100,000 in children aged 5-9 years old, compared to an average rate of 318 per 100,000 in the population [1,2]. Environmental conditions in Bangladesh substantially increase the risk of drowning for children, as much of the country is prone to frequent flooding and waterlogging [3,4]. Many children live close to open water sources such as ponds, rivers and beaches due to high population density coupled with economic dependence on fishing industries [5].

The World Health Organization has recommended the implementation of four community-based interventions that reduce drowning in rural LMIC contexts in response to the United Nation's Sustainable Development Goal 3 to reduce preventable deaths of children under the age of 5 years to 25 per 1000 live births [1,6]. Currently, the under-5 mortality rate in Bangladesh is 34.2 per 1000 live births [7]. Key drowning interventions for young children include the installation of barriers to control access to water (such as playpens and fencing), the provision of safe spaces away from water for pre-school aged children with capable child care, teaching school-aged children basic swimming and rescue skills and training adult bystanders in safe rescue and resuscitation $[1,8]$.

In 2016, the Centre for Injury Prevention and Research, Bangladesh (CIPRB) developed the Project BHASA drowning reduction program based on these identified effective interventions in an effort to reduce the burden of drowning in Bangladesh. Two of these effective interventions within Project BHASA are Anchal and SwimSafe [9]. The Anchal program provides community-based crèches where children aged 1-5 years are cared for within a supervised, protected environment with early childhood development. The SwimSafe program provides survival/basic swimming skills and rescue techniques training to children aged 6-10 years. These reflect WHO recommendations for the provision of safe spaces for pre-school aged children and swim training for school-aged children respectively.

\section{Program Details}

There are three Project BHASA intervention upazilas (sub-districts) in the Barishal division: Kalapara, Taltoli and Betagi upazilas. Evaluation will be conducted across all intervention sites. Upazilas are the lowest level of administrative units in Bangladesh, and typically have a population between 250,000 to 400,000 people.

\subsection{Program A-Anchal Program}

There are 400 Anchal centres under the program across all three intervention upazilas. Each Anchal Centre is managed by a trained Anchal Maa (caregiver of a crèche) and Anchal Assistant (caregiver's assistant) who supervise 20-25 children from 9 a.m. to 1 p.m. six days a week. During this time, children are involved in early childhood development (ECD) activities aimed at stimulating children's physical, intellectual, linguistic, social and emotion development. Children aged 1 to 5 years old are eligible to attend. Anchal centres are held in a suitable room in the Anchal Maa's home, which is equipped with educational materials for child stimulation and barriers to create an enclosed space [10]. Table 1 lists the target number of centres that CIPRB aimed to implement for each upazila. Figure 1 below presents the logic model for Anchal, describing key inputs, outputs and assumptions for this program.

\subsection{Program B-SwimSafe Program}

The SwimSafe program provides children aged 6-10 years of age with a 21-step swimming course delivered in 12 sessions aimed at teaching basic swimming and rescue skills. The program was developed in collaboration with experts from The Alliance for Safe Children, UNICEF and Royal Life Saving Society Australia (RLSSA), catering for contextual requirements [11]. Each session runs for an hour every day until course completion. Classes are provided by 103 trained Community Swimming Instructors (CSIs) in 65 modified ponds. These are local ponds that have been specifically identified 
and modified with bamboo platforms upon which swim classes can be conducted safely. Children attend the classes until they have reached the required competencies, including swimming $25 \mathrm{~m}$ unaided, floating in water for 30 seconds, and demonstration of rescue techniques. Each class is taught in groups of five by one CSI while remaining children watch from outside the pond. SwimSafe classes are held during the monsoon months from mid-June to mid-November [12]. Table 1 lists the target number of centres for each upazila. Figure 2 below presents the logic model for SwimSafe, describing key inputs, outputs and assumptions for this program.

Table 1. Program delivery targets.

\begin{tabular}{ccc}
\hline Upazila & Anchal Centres & SwimSafe Ponds \\
\hline Kalapara & 200 & 33 \\
Taltoli & 80 & 12 \\
Betagi & 120 & 20 \\
\hline
\end{tabular}

\subsection{Monitoring Structures}

Both Anchal and SwimSafe programs are managed at the field level by three levels of staff. Firstly, a total of 20 Supervisors directly manage CSIs and Anchal Staff within their communities. Each Supervisor manages 25-35 Anchal centres or 10-15 ponds and receives a one-day orientation to the program on joining. The ECD component of Anchal is additionally monitored by Anchal Monitoring Officers (AMOs) and an ECD specialist. An Area Coordinator oversees the programs' operations in each upazila, managed by an overarching Program Coordinator. Program trainers are also employed to provide initial and ongoing training to Anchal staff and CSIs. All AMOs and three of the supervisors are female.

CIPRB has also founded Village Injury Prevention Committees (VIPC) in each community. These committees are comprised of local formal and informal leaders. VIPC committees facilitate interactions and engagement between CIPRB and members of the community. VIPC members also oversee the programs' implementation within the community and participate in recruitment of Anchal Maas and CSIs. They are also tasked with raising awareness on drowning prevention in their communities. Committees meet monthly to discuss these issues.

Although both Anchal and SwimSafe have been found to be cost-effective in reducing drowning within communities [9] analysis of the many components of these complex programs and how they contribute to the programs' success has yet to occur. These include investigations of supervision structures, fidelity to program standard operating procedures (SOPs) and monitoring procedures. A process evaluation is thus vital for identifying whether implementation has occurred as intended, and to identify inadequacies and opportunities for improvement in the programs' delivery $[13,14]$. A process evaluation for complex interventions can help explain for whom, how and why the intervention had a particular impact. Such evaluations address the question 'Is this intervention acceptable, effective and feasible for this population?' Gaining a clear understanding of the causal mechanisms of complex interventions is vital in being able to sustain, scale up or deliver an effective intervention in other settings [15]. Therefore, this protocol outlines the frameworks and methodologies that will be used in the process evaluation of Anchal and SwimSafe. 


\begin{tabular}{|c|c|c|c|c|c|c|}
\hline \multirow{2}{*}{ Inputs } & & \multicolumn{2}{|c|}{ Outputs } & \multicolumn{3}{|c|}{ Outcomes } \\
\hline & & Participants & Activities & Short term & Intermediate & Long term \\
\hline $\begin{array}{l}\text { Training for Anchal staff } \\
\text { Funding } \\
\text { Research evidence } \\
\text { Anchal centre locations } \\
\text { identified as appropriate } \\
\text { Teaching materials and } \\
\text { equipment }\end{array}$ & $\frac{\text { c }}{\frac{2}{0}}$ & $\begin{array}{l}\text { Children aged 1-5 who live } \\
\text { within walking distance from } \\
\text { the centre are enrolled } \\
\text { Early childhood education } \\
\text { activities provided in a group } \\
\text { format at the modified } \\
\text { location }\end{array}$ & $\begin{array}{l}\text { Centre location decorated for } \\
\text { child development purposes } \\
\text { Children enrolled into Anchal } \\
\text { program through household } \\
\text { visits } \\
\text { Children attend Anchal } \\
\text { program } 6 \text { days per week }\end{array}$ & $\begin{array}{l}\text { Children reach age- } \\
\text { appropriate developmental } \\
\text { milestones } \\
\text { Children are protected } \\
\text { from water bodies for } 4 \\
\text { hours, } 6 \text { days a week } \\
\text { Parents provide closer } \\
\text { supervision at home due to } \\
\text { less work }\end{array}$ & $\begin{array}{l}\text { Children attend } \\
\text { Anchal centres until } \\
\text { they begin school, and } \\
\text { are protected from } \\
\text { drowning during this } \\
\text { time }\end{array}$ & $\begin{array}{l}\text { Reduced rates of drowning in } \\
\text { the community in } \\
\text { intervention upazilas } \\
\text { Children adapt to the school } \\
\text { environment more readily } \\
\text { Children demonstrate } \\
\text { improved cognitive } \\
\text { development }\end{array}$ \\
\hline $\begin{array}{l}\text { Centre modification } \\
\text { material and labour } \\
\text { set up of community VIPC } \\
\text { committees } \\
\text { Teaching curriculum } \\
\text { Data and attendance } \\
\text { tracking tools } \\
\text { Program coordination and } \\
\text { supervision staff }\end{array}$ & $\begin{array}{l}\frac{ \pm}{\pi} \\
\frac{\omega}{\pi} \\
\frac{\pi}{0} \\
\frac{C}{U} \\
\frac{C}{4}\end{array}$ & $\begin{array}{l}\text { Anchal staff are recruited from } \\
\text { the local community and } \\
\text { trained to deliver educational } \\
\text { curriculum and administer first } \\
\text { aid }\end{array}$ & $\begin{array}{l}\text { Anchal staff run age- } \\
\text { appropriate development } \\
\text { stimulations and tailor } \\
\text { development techniques to } \\
\text { children's competencies } \\
\text { Anchal staff engage VIPC } \\
\text { members, government leaders } \\
\text { and parents during meetings } \\
\text { and before and after classes }\end{array}$ & $\begin{array}{l}\text { Anchal staff develop } \\
\text { relationships with the } \\
\text { community } \\
\text { Anchal staff develop skills } \\
\text { in delivering early } \\
\text { childhood stimulations } \\
\text { Parents appreciate the role } \\
\text { of supervision in drowning } \\
\text { prevention }\end{array}$ & $\begin{array}{l}\text { Anchal staff engage } \\
\text { with the community on } \\
\text { a range of health and } \\
\text { injury-related issues } \\
\text { Anchal staff are better } \\
\text { able to afford day-to- } \\
\text { day living costs and } \\
\text { improve their financial } \\
\text { situation }\end{array}$ & $\begin{array}{l}\text { Increased autonomy, control } \\
\text { and community participation } \\
\text { by Anchal staff. } \\
\text { Communities have more } \\
\text { knowledge of injury } \\
\text { prevention methods and } \\
\text { utilise these }\end{array}$ \\
\hline
\end{tabular}

\section{Assumptions}

- Children will transfer skills learned in Anchal to other environments and locations, including school and social interactions

Anchal Maa remains in role for the duration of the project

Anchal centres are regularly open as per SOP, for 4 hours a day 6 days a week

The majority of children who are approached to participate attend the Anchal centre continuously until they start school

External factors and socio-demographic factors may influence the final results of the program, and so will be measured and analysed through regression models

Anchal staff jobs will not impact other income sources in their household

Anchal staff build positive, long-term relationships with VIPC members and other leaders

Communities are willing and able to learn about injury prevention strategies and implement then

Resources and materials are supplied in a timely, regular manner

Figure 1. Logic model for the Anchal program.

\begin{tabular}{|c|c|c|c|c|c|c|}
\hline \multirow{2}{*}{ Inputs } & & \multicolumn{2}{|c|}{ Outputs } & \multicolumn{3}{|c|}{ Outcomes } \\
\hline & & Participants & Activities & Short term & Intermediate & Long term \\
\hline $\begin{array}{l}\text { Training for CSIs } \\
\text { Funding } \\
\text { Research evidence } \\
\text { Safe local ponds } \\
\text { identified as appropriate } \\
\text { Teaching equipment } \\
\text { Pool modification }\end{array}$ & $\frac{\frac{5}{4}}{\frac{2}{0}}$ & $\begin{array}{l}\text { Children aged 6-10 who live } \\
\text { within walking distance from } \\
\text { a teaching pool are enrolled } \\
\text { Training delivered in group } \\
\text { format at the modified pool } \\
\text { with ratio of } 1 \text { CSI to } 5 \\
\text { children } \\
\text { Children progress through } \\
\text { the } 21 \text {-step curriculum }\end{array}$ & $\begin{array}{l}\text { Pools modified for teaching } \\
\text { purposes } \\
\text { Children enrolled into swim } \\
\text { classes through household } \\
\text { visits } \\
\text { Children attend swim classes } \\
\text { and progress through the } \\
\text { curriculum }\end{array}$ & $\begin{array}{l}\text { Children learn to } \\
\text { swim for } 25 \\
\text { meters unaided } \\
\text { Children learn to } \\
\text { tread water for } 30 \\
\text { seconds unaided } \\
\text { Children } \\
\text { demonstrate land- } \\
\text { based rescue skills }\end{array}$ & $\begin{array}{l}\text { Children use } \\
\text { swimming skills } \\
\text { obtained when } \\
\text { entering water } \\
\text { bodies } \\
\text { Children utilise } \\
\text { rescue skills } \\
\text { independently } \\
\text { when required }\end{array}$ & $\begin{array}{l}\text { Reduced rates of } \\
\text { drowning in } \\
\text { intervention distrcits } \\
\text { Reduced rates of } \\
\text { drowning during } \\
\text { disasters in } \\
\text { intervention distrcits }\end{array}$ \\
\hline $\begin{array}{l}\text { material and labour } \\
\text { Set up of community } \\
\text { VIPC committees } \\
\text { Swimming curriculum } \\
\text { Data and attendance } \\
\text { tracking tools } \\
\text { Program coordination } \\
\text { and supervision staff }\end{array}$ & $\frac{n}{\sqrt{v}}$ & $\begin{array}{l}\text { CSIs are recruited from the } \\
\text { community they are to teach } \\
\text { in and trained to deliver the } \\
\text { curriculum and administer } \\
\text { first aid }\end{array}$ & $\begin{array}{l}\text { CSIs run swimming classes, } \\
\text { and tailor teaching } \\
\text { techniques to children's } \\
\text { competencies } \\
\text { CSIs engage VIPC members, } \\
\text { government leaders and } \\
\text { parents during meetings and } \\
\text { before and after classes }\end{array}$ & $\begin{array}{l}\text { CSIs develop } \\
\text { relationships with } \\
\text { the community } \\
\text { CSIs develop skills } \\
\text { in teaching } \\
\text { Parents appreciate } \\
\text { the role of } \\
\text { swimming skills in } \\
\text { drowning } \\
\text { prevention }\end{array}$ & $\begin{array}{l}\text { CSIs engage with } \\
\text { the community on } \\
\text { a range of health } \\
\text { and injury-related } \\
\text { issues } \\
\text { CSIs are better } \\
\text { able to afford day- } \\
\text { to-day living costs } \\
\text { and improve their } \\
\text { financial situation }\end{array}$ & $\begin{array}{l}\text { Increased } \\
\text { autonomy, control } \\
\text { and community } \\
\text { participation by } \\
\text { CSIs } \\
\text { Communities have } \\
\text { more knowledge of } \\
\text { injury prevention } \\
\text { methods and utilise } \\
\text { these }\end{array}$ \\
\hline \multicolumn{7}{|c|}{ Assumptions } \\
\hline $\begin{array}{ll}\cdot & \text { Children will transfer } \\
\text { - } & \text { The majority of child } \\
\text { - } & \text { External factors and } \\
\text {. } & \text { CSIs jobs will not im } \\
\text { - } \quad \text { CSIs build positive, I } \\
\text { - } \quad \text { Communities are wil }\end{array}$ & & $\begin{array}{l}\text { rned in class to other environm } \\
\text { are approached to participate } \\
\text { nographic factors may influen } \\
\text { income sources in their house } \\
\text { relationships with VIPC memb } \\
\text { ble to learn about injury preve }\end{array}$ & $\begin{array}{l}\text { ints, locations and during disaste } \\
\text { the program complete the prog } \\
\text { the final results of the program, } \\
\text { old } \\
\text { s and other leaders } \\
\text { tion strategies and implement th }\end{array}$ & $\begin{array}{l}\text { etencies } \\
\text { ill be measured }\end{array}$ & 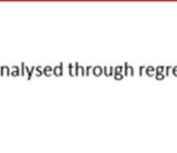 & In models \\
\hline
\end{tabular}

Figure 2. Logic model for the SwimSafe program.

\section{Materials and Methods}

\subsection{Theoretical Approach and Frameworks}

Realist theory posits that programs may have differing effects across contexts and participants. To understand this dynamic, the underlying mechanisms behind the effect of a program requires 
examination $[16,17]$. Underpinned by this realist approach, the current process evaluation will be adapted from the United Kingdom's Medical Research Council [15]. Data collection and analysis will seek to identify the 'true' mechanisms and processes that shape the current status quo, as influenced by the external social and cultural context $[18,19]$.

In addition, comprehensive process evaluations that seek to understand unintended consequences, such as on gender norms and behaviours, are better able to adapt to contexts and ensure maximal effectiveness, while also considering the equity of outcomes [20,21]. Gender analysis will be conducted based on the Gender Integration Framework to comprehensively identify the effect of the programs on gender roles, perceptions and behaviours [22]. The following diagram displays how these frameworks interact to provide a holistic picture. Figure 3 presents a conceptual framework for how the above two frameworks will be brought together develop a comprehensive picture of the programs' implementation success.

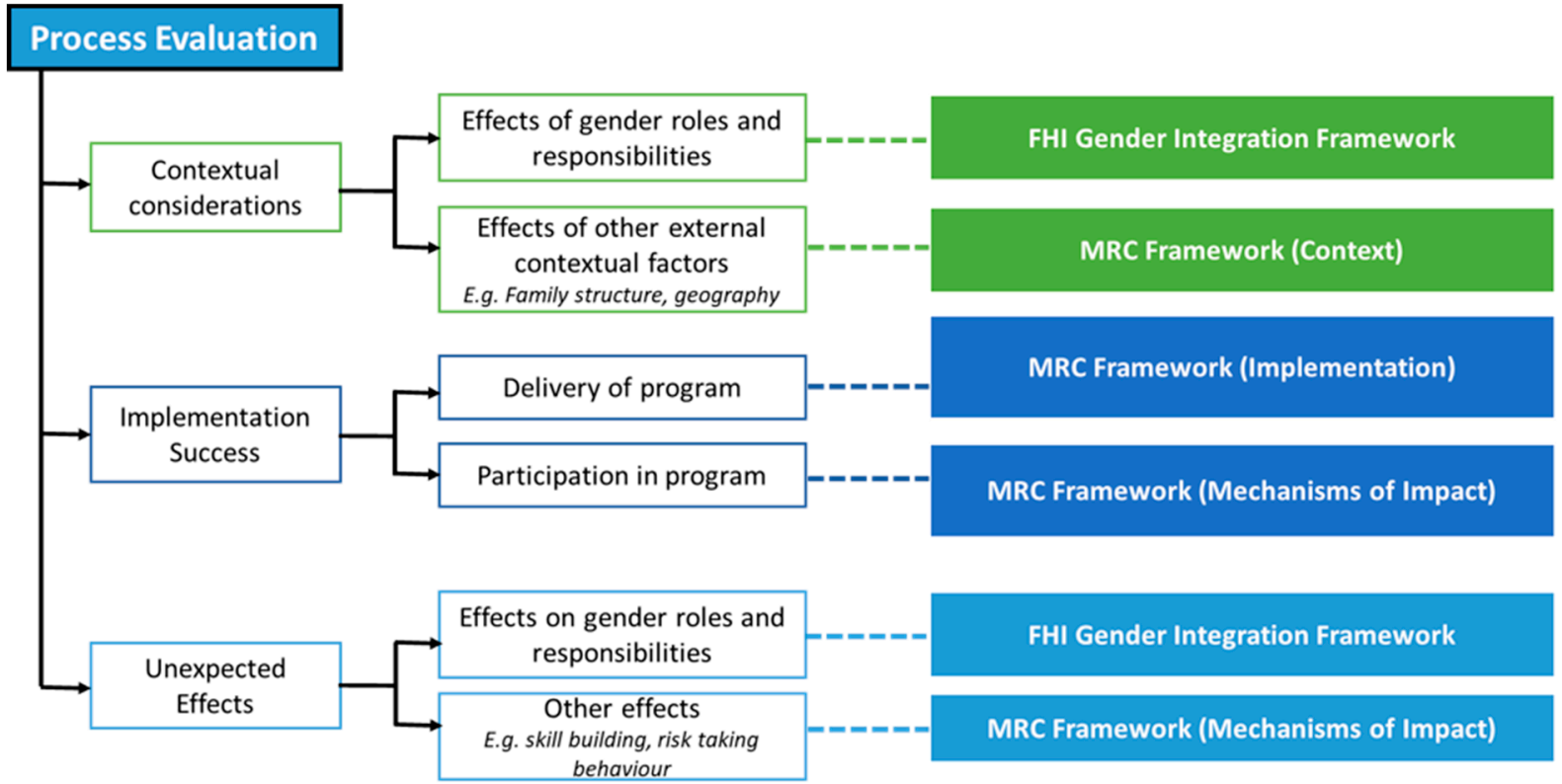

Figure 3. Process Evaluation methodological framework developed for this study.

\subsection{Data Collection}

A mixed- method approach using both quantitative and qualitative data will be used to triangulate the program monitoring data with key informant in-depth interviews (IDIs), focus group discussions (FGDs) and program observations.

\subsubsection{Quantitative Data}

As part of the enrolment process for the programs, staff visit all households in the community and conduct a baseline survey to gather information on the community's demographics. Program monitoring data are also collected, including participant demographics, participant attendance, graduation rates, dropout rates and standardised monitoring forms completed by supervisors. This data is collected and managed using REDCap electronic data capture tools through hand held tablets.

Quantitative data from across the Anchal and SwimSafe programs will be analysed to gather metrics such as child attendance and dropout rates, staff retention and age and gender differences in enrolment. Table 2 outlines these instruments and the quantitative information available from each. 
Table 2. Quantitative data sources for Anchal and SwimSafe.

\begin{tabular}{|c|c|}
\hline Data Source & Variables/Indicators * \\
\hline Baseline Survey & $\begin{array}{c}\text { Types and rates of different reasons for enrolment or non-enrolment } \\
\text { Child demographics in community } \\
\text { Types and rates of different child supervision methods }\end{array}$ \\
\hline Enrolment Form & $\begin{array}{l}\text { Dates of commencement } \\
\text { Demographic characteristics of child } \\
\text { Child skills and interests }\end{array}$ \\
\hline Attendance Book & $\begin{array}{l}\text { Child attendance and drop out } \\
\text { Class cancellations }\end{array}$ \\
\hline Parents Meeting Minutes & $\begin{array}{l}\text { Number and types of complaints } \\
\text { Types and rates of different reasons for drop out } \\
\text { Types and rates of different issues with access to program }\end{array}$ \\
\hline Human Resources Data & $\begin{array}{c}\text { Child attendance } \\
\text { Course completions } \\
\text { Recruitment of program staff } \\
\text { Resignations of program staff } \\
\text { Program staff work hours }\end{array}$ \\
\hline Cluster Meeting book & $\begin{array}{l}\text { Implementation costs and time } \\
\text { Adherence to program operational guidelines } \\
\text { Condition of program locations }\end{array}$ \\
\hline Program Monitoring Forms & $\begin{array}{c}\text { Instances of non-adherence to program operational guidelines } \\
\text { Condition of program locations } \\
\text { Adequacy of resources and equipment }\end{array}$ \\
\hline
\end{tabular}

\subsubsection{Qualitative Data}

The methodology used will be guided by the COREQ guidelines for qualitative research [23]. Qualitative data will be collected by trained data collectors through observation of program delivery and processes, in-depth interviews (IDIs) and focus group discussions (FGDs) in each of the upazilas. IDIs will provide an understanding of individual-level responses to the programs, while FGDs will provide insights to wider community perspectives and cultural norms [24]. Observations provide an opportunity to identify how the program delivery is impacted by context, and captured data on community staff and participant behaviour that is difficult to describe verbally. All data collection will occur face-to-face, unless a participant is not available in person in which case the interview will be conducted over the phone. To build a picture of program provision success and challenges, purposive sampling will be used to select individuals with the most insight to program operations such as community-level staff (Anchal Maas, Anchal Assistants and CSIs), program implementing staff (Supervisors, Area Coordinators, trainers and AMOs) and headquarters staff. To ensure that representative end-user experiences are captured, parents and children who are participating in the program or have otherwise interacted with the program will be randomly selected from communities. Given difficulties in identifying multiple participants in rural LMIC contexts, snowball sampling will be used when recruiting for focus groups after the initial two or three participants are randomly selected, utilising community knowledge to gather others with insights.

The exact sample size for each participant type cannot be determined a priori. Data collection will cease once saturation has been reached [25]. This will be assessed by the investigators in daily de-brief meetings held with the data collection team. These debriefs will be important to identify key emerging themes that require further clarification or investigation, continually build data collection capabilities and plan strategies for purposive participant selection as most relevant to the local context [26]. Variations in key findings across participant groups and geographic areas will be also be discussed during daily debriefings. Appropriate participation selection strategies that increase variation and seek clarification will be implemented. Table 3 below presents how the various components of the evaluation will be assessed with these data collection methods. 
Table 3. Process measures and key questions.

\begin{tabular}{|c|c|c|c|c|}
\hline MRC Component & Sub-Component & Key Questions & $\begin{array}{c}\text { Source of } \\
\text { Information }\end{array}$ & Key Measures \\
\hline Context & $\mathrm{N} / \mathrm{A}$ & $\begin{array}{l}\text { How does context shape the needs and experiences of } \\
\text { participants and staff, and affect program } \\
\text { implementation? }\end{array}$ & $\begin{array}{l}\text { IDIs and FGDs } \\
\text { Observations }\end{array}$ & $\begin{array}{l}\text { Participant, staff, family and community experiences } \\
\text { and perspectives }\end{array}$ \\
\hline \multirow{5}{*}{ Implementation } & Processes & $\begin{array}{l}\text { Are support processes such as training, data collection } \\
\text { and supply chain management sufficient to support } \\
\text { implementation? }\end{array}$ & $\begin{array}{l}\text { Program data } \\
\text { IDIs and FGDs }\end{array}$ & $\begin{array}{l}\text { Staff experiences and perspectives } \\
\text { Efficiency of program delivery }\end{array}$ \\
\hline & Reach & $\begin{array}{l}\text { Do the programs access different demographic groups } \\
\text { (ethnicity, religion gender, age) equally? } \\
\text { Who is being missed by the programs? }\end{array}$ & $\begin{array}{l}\text { Program data } \\
\text { IDIs and FGDs }\end{array}$ & $\begin{array}{l}\text { Comparison of the socio-demographic characteristics } \\
\text { participants and non-participants } \\
\text { Descriptions of challenges faced when accessing the } \\
\text { programs }\end{array}$ \\
\hline & Fidelity & $\begin{array}{l}\text { Were the programs being implemented as intended in a } \\
\text { consistent way across sites? }\end{array}$ & $\begin{array}{l}\text { IDIs and FGDs } \\
\text { Observations }\end{array}$ & $\begin{array}{l}\text { Comparison of delivery processes across sites } \\
\text { Descriptions of the site-wise adaptations throughout } \\
\text { implementation }\end{array}$ \\
\hline & Dose delivered & $\begin{array}{l}\text { Do the programs deliver sufficient services to meet } \\
\text { delivery targets? }\end{array}$ & $\begin{array}{l}\text { Program data } \\
\text { IDIs and FGDs } \\
\text { Observations }\end{array}$ & $\begin{array}{l}\text { Number of sites } \\
\text { Number of operational and non-operational days per } \\
\text { site } \\
\text { Reasons for non-delivery (e.g., due to weather, pond } \\
\text { condition, lack of staff etc.) }\end{array}$ \\
\hline & Adaptations & $\begin{array}{l}\text { How is the program adapted to different sites across the } \\
\text { program? }\end{array}$ & $\begin{array}{l}\text { IDIs and FGDs } \\
\text { Observations }\end{array}$ & Comparison of program processes between sites \\
\hline \multirow[t]{2}{*}{ Mechanisms of impact } & $\begin{array}{l}\text { Participant responses and } \\
\text { interactions }\end{array}$ & $\begin{array}{l}\text { Do participants engage with the programs for continued } \\
\text { use? Were the programs acceptable interventions at the } \\
\text { micro, meso and macro levels? }\end{array}$ & $\begin{array}{l}\text { Program data } \\
\text { IDIs and FGDs } \\
\text { Observations }\end{array}$ & $\begin{array}{l}\text { Participant registrations, attendances, completions } \\
\text { and drop-outs } \\
\text { Reasons for drop-outs } \\
\text { Comparison of socio-demographic factors for } \\
\text { low-dose and high-dose participants } \\
\text { Participant, staff, family and community experiences } \\
\text { and perspectives }\end{array}$ \\
\hline & Unexpected consequences & $\begin{array}{l}\text { What are some unexpected benefits and issues caused } \\
\text { by the program? } \\
\text { Are there any unanticipated harms or dangers } \\
\text { associated with the program? }\end{array}$ & $\begin{array}{l}\text { IDIs and FGDs } \\
\text { Observations }\end{array}$ & $\begin{array}{l}\text { Participant, staff, family and community experiences } \\
\text { and perspectives }\end{array}$ \\
\hline
\end{tabular}




\subsection{In-Depth Interviews}

Implementing staff from CIPRB will introduce the data collectors to the community. Communities will be purposively selected to ensure that the evaluation includes sites with a variety of geographic, demographic and program characteristics. Within communities, parents and children will be randomly selected by data collectors, while program staff will be purposively selected based on their roles. The interviews will last between $30-60 \mathrm{~min}$ and be conducted in a quiet place such as a participant's home or local office. Only data collectors and participants will be present.

\subsection{Focus Groups (FGDs)}

Each FGD will comprise of 6-8 participants and will last for 40-60 min. Researchers will purposively select program staff or randomly select children and parents for FGDs and then use snowballing to identify further participants. FGDs will be homogenous and comprise of one type of participant of the same gender, such as mothers of participating children, or male CSIs only. FGDs will be held in a neutral place such as a school or community hub.

\subsection{Observations}

There are four major components of the programs that will be observed by the research team, which are (1) review of the programs' documented SOPs; (2) program delivery venues; (3) delivery of programs to children; and (4) supervision visits of the Anchal Maas, Anchal Assistants and CSIs.

The observations will incorporate shadowing techniques where data collectors will use prompts to ask participants their motivations behind behaviours when feasible to do so without interrupting the session [27].

Female data collectors will conduct observations of Anchal centre operations from 9 a.m. to 1 p.m. or SwimSafe classes from the side of the pond. They will note observations in an observational checklist, which will be developed based on program SOP requirements and monitoring outcomes such as venue suitability and maintenance, Anchal staff and CSI behaviour with children, and child responsiveness to the program. Data collectors will be present at the venue before the sessions start and will remain throughout to minimize interruption.

\subsection{Data Collection Managmenet}

The IDIs and FGDs will take a semi-structured format using interview guides that will be developed in accordance with the study objectives and field-testing. See Appendices A and B for example interview guides developed. Data collectors will take notes of main points during all IDIs and FGDs, and these will be audio recorded if participants consent. All data collectors are fluent in Bengali, and have previous training and experience in qualitative data collection in the Barishal division through previous research work with CIPRB. Data collectors are employed full time by CIPRB, and have previous relationships with the program staff. Two male data collectors and two female data collectors will be engaged.

All IDIs and FGDs will be first transcribed in Bengali and then translated to English. 20\% of translations will be checked by the data collectors for quality assurance. Transcriptions will not be returned to participants due to limitations in literacy of participants and logistical constraints in re-visiting communities and locating individuals.

\subsection{Consent}

Free and informed written consent will be sought from all participants. All participants will be informed that the data will be used to improve the delivery of the Anchal and SwimSafe programs. The voluntary nature of the study will be emphasised. Participants will also specifically indicate that they consent to being audio recorded. Written consent for child participants will be obtained from their parents or guardian. 


\section{Analysis}

\subsection{Process Evaluation}

The primary aim of the process evaluation is to understand who benefits from the programs and under what conditions. Accordingly, the process evaluation will answer key questions about the barriers and enablers for the implementation and uptake of the programs in the Barishal division. These will be structured around context, implementation and mechanisms of impact as per the United Kingdom's Medical Research Council guide to process evaluations [15]. These components are in line with other common frameworks for process evaluations $[28,29]$. The measures for these domains are described in Table 3 above. Additionally, the analysis will be used to identify bottlenecks to accessing the program and receiving its full benefits. Bottlenecks are defined as those determinants or factors that constrain coverage of the intervention. Bottleneck determinants can be classified according to UNICEF's Monitoring Results for Equity Systems (MoRES) under four domains [30]. These domains are Enabling Environment (including social norms, policy and budget), Supply (including availability of inputs and access to services and facilities), Demand (including financial access and continuity of use) and Quality of services.

\subsection{Gender Analysis}

To identify unexpected benefits (or harms) related to gender, this process evaluation will be seeking to identify how the programs have affected the gendered roles and relationships within the communities in which they operate, including impacts for parents, program staff and other community members. Gender analysis provides insight into benefits of programs beyond the targeted effect, and can lead to the identification of possible opportunities to promote gender equity in both the program implementation team and targeted communities [20].

We will undertake a gender analysis informed by the Gender Integration Framework by FHI 360 upon which questions will be developed for IDIs and FGDs [22]. Specific questions that explore each of the five domains will be incorporated into the data collection tools. The Gender Integration Framework is specifically designed to analyse gender dynamics in development programs. This framework will allow for the analysis of the roles that men, women, boys and girls play within the program and wider community, and how these interact with power imbalances and affect opportunities, needs, constraints and relationships across the five key domains outlined in Table 4 .

Table 4. Gender Integration Framework domains.

\begin{tabular}{ccl}
\hline Domain & Sources of Information & \multicolumn{1}{c}{$\begin{array}{c}\text { Examples of Key Gender Relations, } \\
\text { Barriers and Opportunities }\end{array}$} \\
\hline 1. Access to resources & $\begin{array}{c}\text { Program Data } \\
\text { IDIs and FGDs } \\
\text { Observations }\end{array}$ & $\begin{array}{l}\text { Education, information, services, } \\
\text { employment, benefits, freedom of } \\
\text { movement, transport }\end{array}$ \\
\hline 2. Knowledge, beliefs, perceptions & $\begin{array}{c}\text { IDIs and FGDs } \\
\text { Observations }\end{array}$ & $\begin{array}{l}\text { Beliefs about capabilities, self-efficacy and } \\
\text { confidence, acceptable behaviour and value } \\
\text { in society, child safety and protection }\end{array}$ \\
\hline 3. Practices and participation & IDIs and FGDs & $\begin{array}{l}\text { Autonomy and time to participate both } \\
\text { within the home and in the community, types } \\
\text { of activities and practices }\end{array}$ \\
\hline 4. Legal rights and status & Program Data & $\begin{array}{l}\text { Employment contracts and rights, biases in } \\
\text { governance and policy at program and } \\
\text { institutional level }\end{array}$ \\
\hline 5. Power & IDIs and FGDs & $\begin{array}{l}\text { Autonomy, household financial control, } \\
\text { control over resources, decision making } \\
\text { within the household and in the community }\end{array}$ \\
\hline
\end{tabular}


It is important that gender analysis be accompanied by action to address imbalances in gender power relations. We will use the findings from the gender analysis to identify how gender inequities can be addressed through practical strategies in the programs which will be implemented in mid-2019.

\subsection{Data Analysis Methods}

Quantitative data collected from program records will be analysed to determine specific process measures such as reach, fidelity and dose. Descriptive analysis such as counts and percentages will be conducted for this data to identify demographic differences between outcomes such as attendance and graduation rates. Differences in rates and proportions between groups will be analysed using bivariate Pearson Chi-squared tests and trends analysed using Chi-square linear-by-linear associations. The SPSS statistical software package will be used to conduct the analysis [31].

Analysis of the transcribed qualitative data will be assisted by NVivo 12 software [32]. A framework method of analysis will be used to generate categories and codes and will incorporate both deductive (pre-determined) and inductive (developed) analysis. This approach allows for the exploration of specific themes (e.g., barriers and facilitators of implementation) while not restricting the emergence of unanticipated themes $[25,33]$. As per the realist approach, the inductive process will seek to identify patterns in the qualitative data set that are reflective of the true underlying mechanisms affecting the programs' delivery and response [18]. The quantitative and qualitative data will be drawn together to provide a contextualised understanding of who benefits from the programs and under what conditions. Qualitative analysis will be conducted independently by two separate teams. Discrepancies in findings will be discussed once independently analysis has concluded.

Quantitative and qualitative data will be presented together to illustrate program implementation status, encompassing both key successes and issues in regards to program delivery, management and community response. Quantitative data will provide insights into the current status of these implementation components, and the qualitative findings will identify the mechanisms behind these and potential strategies for improvement

All data will be stored and shared via secured servers. All files will be de-identified before sharing with translators or being used for analysis. Data will be stored for five years in the secured servers and physical cabinets for 5 years, as per Australian research ethics requirements [34].

\section{Ethics Approval and Consent to Participate}

Local ethics approval from the ethics committee of CIPRB has been granted (Memo no: CIPRB/ERC/2017/24). Ethical approval was also obtained from the University of New South Wales Human Research Ethics Committee (HC: 180608). Written informed consent will be obtained from all participants for qualitative data collection. Consent will be taken from parents or guardians of minors participating in the study.

The findings of the analysis will be presented in a report to the funder of the programs and CIPRB program staff. Findings will also be verbally shared with community VIPC members by Supervisors to gain their assistance in improving implementation. The results will additionally be published in peer-reviewed journals and presented at academic conferences.

\section{Discussion}

This protocol outlines in detail the methodology, methods, and analyses that will be used to conduct a process evaluation of the Anchal and SwimSafe drowning reduction programs in the Barishal division of Bangladesh. This process evaluation will explore the implementation of these programs through analysis of its delivery and effect on gender roles and responsibilities [20,22]. The results of this evaluation will be useful for the quality assurance and improvement of these programs. Firstly, the process evaluation components will allow the implementers to identify and remedy inadequacies in their delivery and supervision of the program, as well as better tailor program delivery to the expectations and requirements of program participants. The gender analysis will provide insights into 
the programs' effect on gender roles and relationships, and allow the program to be better designed to address gender inequities.

The results may additionally guide other organisations seeking to implement community-based drowning reduction programs in LMICs by providing insights into key considerations and challenges when delivering these programs.

\section{Strengths and Limitations}

This project will engage a variety of relevant stakeholders, from participants to program delivery staff to supervisory staff, to obtain a thorough representation of the current implementation status of Anchal and Swimsafe programs. Furthermore, the incorporation of the Gender Integration Framework in the analysis allows for a more holistic view of unanticipated benefits and harms, beyond the scope of traditional process evaluations.

A key challenge for this study will be the translation of qualitative responses into English for analysis, introducing the possibility of incorrect semantics and meaning being represented in the transcripts. It is essential that key findings be compared to field notes and corroborated with Bengali-speaking data collectors to ensure no mistranslations have occurred. Data collectors will crosscheck a random selection of translated transcripts $(20 \%)$ against their notes to ensure that appropriate meaning is being conveyed $[35,36]$. The data will be evaluated for usability once obtained to ascertain its appropriateness for analysis. Additionally, all available data from across the programs will be used in the quantitative analysis and triangulated with qualitative data to find common issues in our results. Another limitation is that the presence of data collectors at community Anchal and SwimSafe sessions may impact behaviour of community members. Hence, it will be important to cross-validate observations made with accounts from IDIs and FGDs of session operations. Lastly, we may face challenges in gathering a representative sample of participants for qualitative data collection. For example, parents with above-average negative or positive experiences of the programs may be more likely to participate. It is essential that qualitative data collection only ceases when new concepts are no longer being identified. Our sample selection is purposively guided to ensure maximal variance. In particular, daily debriefing sessions will provide an opportunity for data collection and investigation teams to collaboratively solve issues in the field in real time. It will also be imperative to prevent groupthink during debriefs by following a structured agenda where data collectors first present findings from their notes, and then discuss the implications after all points have been shared.

Author Contributions: M.G. collaborated with other authors and conducted peer review searches to identify analysis frameworks. M.G. and J.J. drafted the manuscript. A.R., K.u.B., S.H. and F.R. provided subject matter expertise on the programs and context to guide development of appropriate methods. A.B.Z. provided guidance on framework selection and design of study. All authors contributed to the development of the protocol and approved the final version of the manuscript submitted for publication.

Funding: This project is funded by the Royal National Lifeboat Institution (RNLI) UK. RNLI provided guidance on key research questions and data collection methods at the inception of this protocol. Anchal and SwimSafe programs are implemented by the Centre for Injury Prevention and Research, Bangladesh (CIPRB), Bangladesh.

Acknowledgments: We thank Patricia Cullen for her support during the original brainstorming for this protocol. We also thank Soumyadeep Bhaumik for reporting on current program monitoring systems for the design of this protocol. This protocol has not been peer-reviewed by the funder.

Conflicts of Interest: The authors declare no conflicts of interest. 


\section{Appendix A.}

\section{Appendix A.1. Example Guide of IDI}

\section{Anchal Interview Guide}

Table A1. Anchal Maa.

\begin{tabular}{|c|c|c|}
\hline & & Eligibility Criteria \\
\hline \multicolumn{3}{|l|}{ Village/Site } \\
\hline \multicolumn{3}{|l|}{ Gender } \\
\hline \multicolumn{3}{|l|}{ Age } \\
\hline \multicolumn{3}{|l|}{ 1. Roles and responsibilities } \\
\hline Demographic information & & $\begin{array}{l}\text { How long have you been working as an Anchal Maa? } \\
\text { What is your educational background? }\end{array}$ \\
\hline \multirow[t]{3}{*}{ Centre location } & $\begin{array}{l}3 . \\
4 . \\
5 .\end{array}$ & $\begin{array}{l}\text { Are you from the same community you work in? } \\
\text { How was your centre location selected? } \\
\text { How appropriate do you think the location is for running a centre? }\end{array}$ \\
\hline & & a. Why? \\
\hline & 6. & How have you changed delivery of your class to cater for your community? \\
\hline \multirow{3}{*}{ Operations and activities in class } & $\begin{array}{l}7 . \\
8 . \\
9 . \\
10 .\end{array}$ & $\begin{array}{l}\text { Can you tell me about your role as an Anchal Maa? } \\
\text { How often do you open your Anchal Centre? } \\
\text { Can you tell me what activities happen in an Anchal class? } \\
\text { Do you (Anchal Ma) cancel/postponed any classes? }\end{array}$ \\
\hline & & $\begin{array}{l}\text { a. If yes, } \\
\begin{array}{ll}\text { i. } \quad \text { Why do you cancel? } \\
\text { ii. How do you inform parents the class is cancelled? }\end{array}\end{array}$ \\
\hline & $\begin{array}{l}11 . \\
12 . \\
13 . \\
14 .\end{array}$ & $\begin{array}{l}\text { What kind of activities do you do with the children? } \\
\text { Can you comment on the adequacy of the equipment for running activities and } \\
\text { feeding children? } \\
\text { What challenges do you face when conducting activities for children? } \\
\text { How confident are you in your ability to rescue children from drowning and } \\
\text { administer first aid on children? }\end{array}$ \\
\hline \multicolumn{3}{|l|}{ 2. Recruitment and training } \\
\hline \multirow[t]{4}{*}{ Recruitment process } & $\begin{array}{l}15 . \\
16 . \\
17 . \\
18 . \\
19 .\end{array}$ & $\begin{array}{l}\text { Why did you become an Anchal Maa? } \\
\text { How did you hear about this job? } \\
\text { What was the application and interview process to apply for this job? } \\
\text { Before becoming an Anchal Maa, what did you have to talk about with your family? } \\
\text { How does your family respond to you doing this job? }\end{array}$ \\
\hline & & a. Why do they respond in this way? \\
\hline & 20. & How does your family think about this job? \\
\hline & & a. Probe for: Women's roles, employment of women \\
\hline \multirow{4}{*}{ Training } & 21. & Can you describe the training your received? \\
\hline & & a. Probe: Time, topics, training method, trainer skills \\
\hline & 22. & How can the training be improved for Anchal Maa's? \\
\hline & & Probe: Timings, new topics \\
\hline
\end{tabular}


Table A1. Cont.

\begin{tabular}{|c|c|c|}
\hline & & Eligibility Criteria \\
\hline \multirow{7}{*}{ Support } & \multirow[t]{5}{*}{23.} & $\begin{array}{l}\text { If you have a problem or question, what is the process for getting it resolved from the } \\
\text { office? }\end{array}$ \\
\hline & & Probe for \\
\hline & & Methods of contacting supervisors \\
\hline & & Time taken to respond \\
\hline & & iii. Quality of support provided by supervisor \\
\hline & \multirow[t]{2}{*}{24.} & $\begin{array}{l}\text { How supported do you supported by your Supervisor when you have a problem or } \\
\text { question? }\end{array}$ \\
\hline & & Why? \\
\hline \multicolumn{3}{|l|}{ 3. Perceived value } \\
\hline \multirow{4}{*}{ Value } & 25. & Do you think every child aged 1-5 years old should attend an Anchal Centre? \\
\hline & & Why or Why not? \\
\hline & 26. & Does Anchal protect children from drowning? \\
\hline & & a. Why or why not? \\
\hline \multicolumn{3}{|l|}{ 4. Child attendance } \\
\hline \multirow[t]{4}{*}{ Attendance and performance } & $\begin{array}{l}27 . \\
28 . \\
29 . \\
30 . \\
31 . \\
32 . \\
33 .\end{array}$ & $\begin{array}{l}\text { Do all children attend in Anchal regularly? } \\
\text { How many children attend the Anchal regularly? } \\
\text { How many children are registered in Anchal, but do not attend regularly? } \\
\text { What sort of strategies help a child attend regularly? } \\
\text { What prevents children from attending regularly? } \\
\text { Can you describe any differences in how girls and boys learn at your centre? } \\
\text { Can you tell us any differences you find in performing considering age? }\end{array}$ \\
\hline & & a. Probe: $1-2$ years old, $3-5$ years old \\
\hline & 34. & What is your experience in looking after children of all ages from $1-5$ years old? \\
\hline & & Probe for challenges \\
\hline \multicolumn{3}{|l|}{ 5. Effect on everyday life } \\
\hline \multirow{4}{*}{ General Impacts } & $\begin{array}{l}35 . \\
36 .\end{array}$ & $\begin{array}{l}\text { How has being an Anchal Maa changed your day to day life? } \\
\text { What are the positive benefits of being an Anchal Maa? }\end{array}$ \\
\hline & & $\begin{array}{l}\text { a. Compared to other women in your community, what advantages has being an } \\
\text { Anchal Maa given you? }\end{array}$ \\
\hline & 37. & What are the negative consequences of being an Anchal Ma? \\
\hline & & $\begin{array}{l}\text { a. Compared to other women in your community, what disadvantages has being } \\
\text { an Anchal Maa given you? }\end{array}$ \\
\hline \multirow[t]{2}{*}{ Resources } & 38. & $\begin{array}{l}\text { How has being an Anchal Maa changed which resources you have access to at home } \\
\text { and how you access them? }\end{array}$ \\
\hline & & a. Probe: Food, medicines, supplies for any children \\
\hline Control & 39. & How has becoming an Anchal Maa changed your role in family decision making? \\
\hline Practices and participation & 40. & $\begin{array}{l}\text { How has becoming an Anchal Maa changed the housework you do and how } \\
\text { housework is divided? }\end{array}$ \\
\hline Community involvement & 41. & $\begin{array}{l}\text { How has being an Anchal Maa changed your involvement in the community? For } \\
\text { example participation in festivals, village governance committees and community } \\
\text { decision making. }\end{array}$ \\
\hline
\end{tabular}


Table A1. Cont.

\begin{tabular}{lll}
\hline & \multicolumn{2}{c}{ Eligibility Criteria } \\
\hline 42. & $\begin{array}{l}\text { As a woman, how does being and Anchal Maa change your status or role in your } \\
\text { community and at home? }\end{array}$ \\
& a. $\quad$ Probe for \\
& i. $\quad$ Changes in household work \\
& ii. $\quad$ Changes in mobility in their community \\
& iii. $\quad$ Involvement in community activities \\
& iv. Control over money and their time
\end{tabular}

43. Can you describe the process you take to enrol children?

a. Probe for detail

Enrolment

i. How often they look to enrol children

ii. How they select who to approach

44. Can you describe any difficulties you've had with the enrolment process?

45. How can enrolment processes be improved?

46. Can you describe what data you collect?

a. For each type of data collected, probe

i. How do you record the data?

ii. How do you report the data?

Data collection types

47. What components of the data collection process are easy to complete?

a. What makes them easy?

48. Can you describe any parts of the data collection process that are difficult?

a. Why are they difficult?

b. How can they be improved?

7. Engagement with community

49. Can you describe the process for setting up and conducting meetings you have with parents?

a. Probe

Parent meetings

i. Contents of meetings

ii. Frequency

iii. Proportions of fathers and mothers

50. Are parents interested in attending the meetings?

a. Why or why not?

Parent problems

VIPC Meetings
51. What do parents like about Anchal?

52. What are some of the problems that parents have with Anchal?

53. Can you describe the meetings you have with the VIPC?

a. Probe
i. $\quad$ Contents of meetings
ii. Frequency
iii. Proportions of fathers, mothers and others

54. How do you and the VIPC work together?

a. Probe: child enrolment, awareness on drowning and injury

55. Can you give an example of how you and the VIPC have changed or improved the program in your community? 
Table A1. Cont.

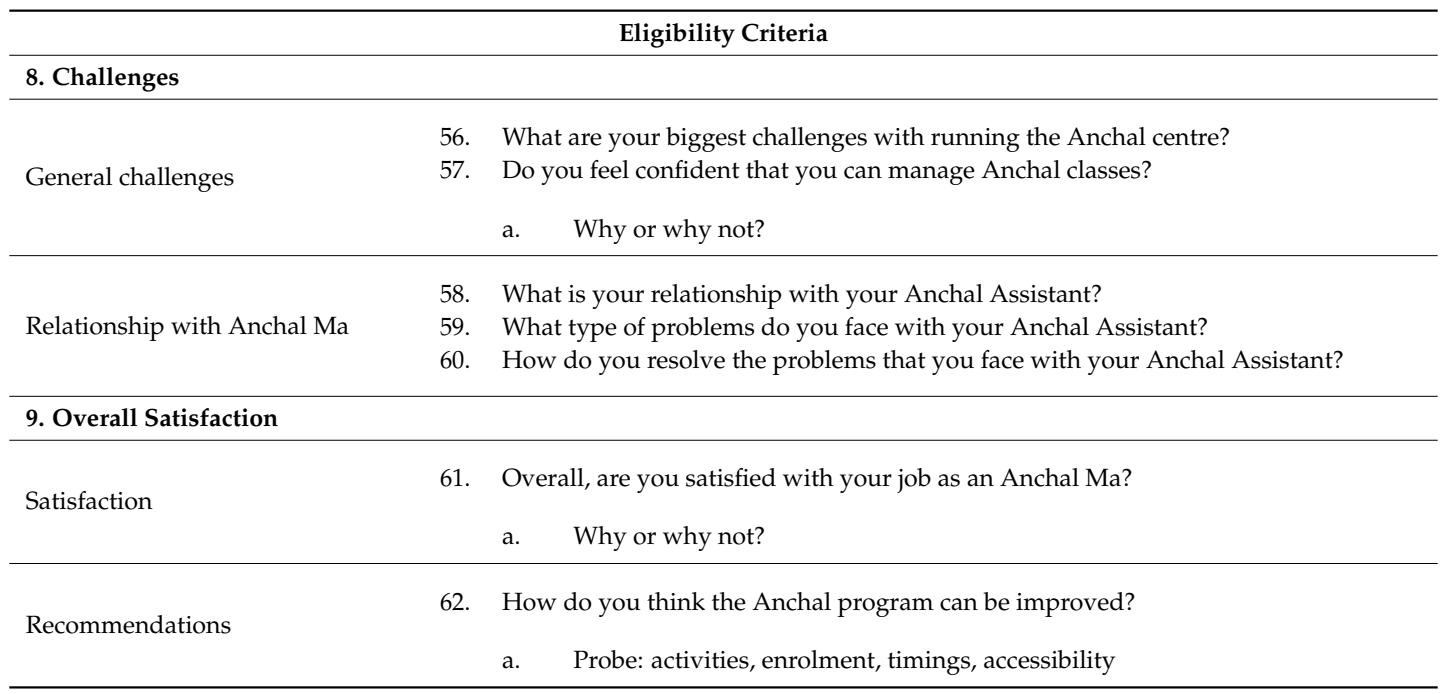

\section{Appendix B.}

\section{Appendix B.1. Example Guide of FGD Guide}

\section{Swimsafe Focus Group Guide}

Table A2. Parents of graduated and enrolled children.

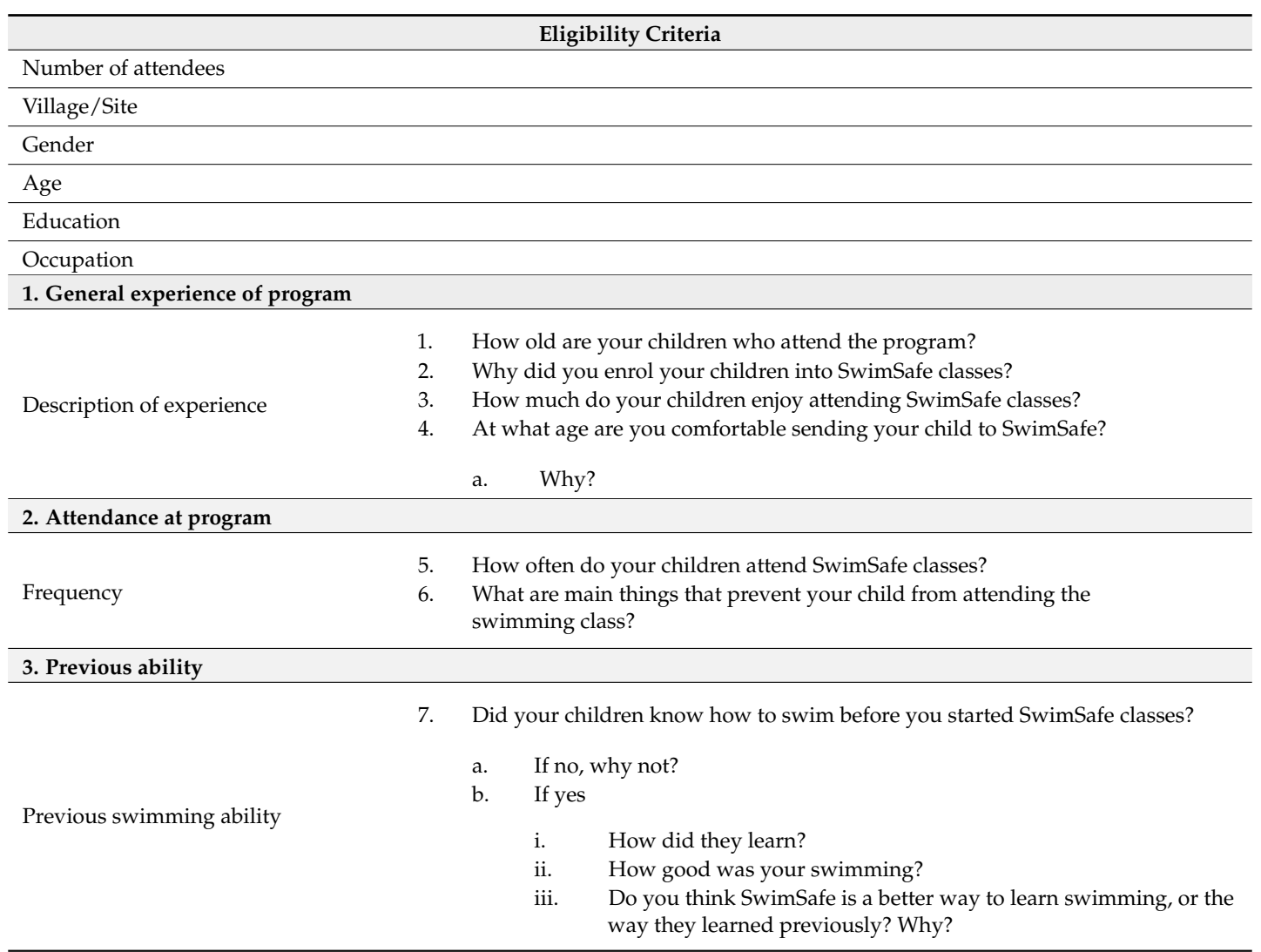


Table A2. Cont.

\begin{tabular}{|c|c|c|}
\hline \multicolumn{3}{|r|}{ Eligibility Criteria } \\
\hline 4. Program orientatic & & \\
\hline \multirow{9}{*}{ Enrolment Process } & 8. & How do you come to know about this program? \\
\hline & & Probe: Different places from where they heard about the program? \\
\hline & 9. & Do you attend any awareness sessions conducted by the program? \\
\hline & & If yes, then explore the total procedure of the awareness session. \\
\hline & 10. & What are the reasons to involve your child/children in this program? \\
\hline & 11. & Who made the decision for your child/children to get involved in this program? \\
\hline & 12. & $\begin{array}{l}\text { What are the procedures you followed to enrol into the program and begin } \\
\text { attending classes? }\end{array}$ \\
\hline & 13. & Have you attended any SwimSafe sessions? \\
\hline & & $\begin{array}{l}\text { a. If yes, what did you do and see in this session? } \\
\text { b. If no, why have you not attended a SwimSafe session? }\end{array}$ \\
\hline \multicolumn{3}{|l|}{ 5. Perceived value } \\
\hline \multirow{5}{*}{ Value } & 14. & Do you think every child should do the SwimSafe classes? \\
\hline & & a. Why or Why not? \\
\hline & 15. & $\begin{array}{l}\text { How effective do you think SwimSafe has been in keeping your children safe } \\
\text { from drowning? }\end{array}$ \\
\hline & 16. & Do you think that SwimSafe is beneficial to the community in other ways? \\
\hline & & $\begin{array}{l}\text { a. If yes, what benefits does it bring? } \\
\text { b. If no, why not? }\end{array}$ \\
\hline \multirow{2}{*}{ General experiences } & 17. & $\begin{array}{l}\text { Can you tell me about any bad experiences you have had with the } \\
\text { SwimSafe classes? }\end{array}$ \\
\hline & 18. & Can you tell me about any positive experiences you have had with the program? \\
\hline \multicolumn{3}{|c|}{ 6. Components of the program } \\
\hline \multirow{5}{*}{ CSI } & $\begin{array}{l}19 . \\
20 .\end{array}$ & $\begin{array}{l}\text { What do you think about the swimming instructors? } \\
\text { What is your satisfaction level with the swimming instructors? }\end{array}$ \\
\hline & & Why? \\
\hline & 21. & $\begin{array}{l}\text { Do you think men or women are more suited to be swim trainers, or do you think } \\
\text { they are equally suited? }\end{array}$ \\
\hline & & Probe for beliefs about women's roles and abilities \\
\hline & 22. & Do you have any recommendations for how swimming instructors can improve? \\
\hline Access challenges & $\begin{array}{l}23 . \\
24 . \\
25 .\end{array}$ & $\begin{array}{l}\text { Can you describe how your child travel to SwimSafe class? } \\
\text { Are there any problems your child faces with the way they access the class? } \\
\text { Do you have any recommendations for how access to the swim classes can } \\
\text { be improved? }\end{array}$ \\
\hline Pool & $\begin{array}{l}26 . \\
27 .\end{array}$ & $\begin{array}{l}\text { What do you think of the pond the lessons are held in? } \\
\text { Do you have any recommendations for how the pond for classes can } \\
\text { be improved? }\end{array}$ \\
\hline
\end{tabular}

28. Would you recommend this program to other parents?

$$
\text { a. Why or why not? }
$$

Recommendations

29. Do you have any other recommendations for how the SwimSafe program can improve?

29. Do you have any recommendations for how the SwimSafe program might attract more children and parents?

30. Do you have any recommendations for how SwimSafe can make it easier for parents to register and send their children?

\section{References}

1. Meddings, D.; Hyder, A.A.; Ozanne-Smith, J.; Rahman, A. Global Report on Drowning: Preventing a Leading Killer; World Health Organization: Geneva, Switzerland, 2014. 
2. Rahman, A.; Alonge, O.; Bhuiyan, A.-A.; Agrawal, P.; Salam, S.S.; Talab, A.; Rahman, S.Q.; Hyder, A.A. Epidemiology of Drowning in Bangladesh: An Update. Int. J. Environ. Res. Public Health 2017, $14,488$. [CrossRef] [PubMed]

3. Monastersky, R. Geography Conspires Against Bangladesh. Science News, 11 May 1991; Volume 139, p. 295.

4. Rahman, A.; Rahman, A.K.M.F.; Shafinaz, S.; Linnan, M. Bangladesh Health and Injury Survey: Report on Children; Ministry of Health \& Family Welfare, Government of the People's Republic of Bangladesh: Dhaka, Bangladesh, 2005.

5. Callaghan, J.A.; Hyder, A.A.; Khan, R.; Blum, L.S.; Arifeen, S.; Baqui, A.H. Child supervision practices for drowning prevention in rural Bangladesh: A pilot study of supervision tools. J. Epidemiol. Community Health 2010, 64. [CrossRef] [PubMed]

6. United Nations. Sustainable Development Goals; United Nations Development Program: New York, NY, USA, 2015.

7. UNICEF. Country Profile: Bangladesh. New York, USA; UNICEF Data: 2018. Available online: https: / / data.unicef.org/country/bgd/ (accessed on 23 June 2018).

8. World Health Organization. Preventing Drowning: An Implementation Guide; World Health Organization: Geneva, Switzerland, 2017.

9. Rahman, F.; Bose, S.; Linnan, M.; Rahman, A.; Mashreky, S.; Haaland, B.; Finkelstein, E. Cost-Effectiveness of an Injury and Drowning Prevention Program in Bangladesh. Pediatrics 2012, 130, e1621-e1628. [CrossRef] [PubMed]

10. Centre for Injury Prevention and Research Bangladesh. Anchal. Available online: http://www.ciprb.org/ anchal/ (accessed on 25 May 2018).

11. Centre for Injury Prevention and Research Bangladesh. Bangladesh. Available online: http://swimsafe.org/ swimsafe-projects/bangladesh/ (accessed on 1 June 2018).

12. Centre for Injury Prevention and Research Bangladesh. SwimSafe. Available online: http://www.ciprb.org/ swimsafe/ (accessed on 25 May 2018).

13. Campbell, M.; Fitzpatrick, R.; Haines, A.; Kinmonth, A.L.; Sandercock, P.; Spiegelhalter, D.; Tyrer, P. Framework for design and evaluation of complex interventions to improve health. BMJ 2000, 321, 694-696. [CrossRef] [PubMed]

14. Koorts, H.; Eakin, E.; Estabrooks, P.; Timperio, A.; Salmon, J.; Bauman, A. Implementation and scale up of population physical activity interventions for clinical and community settings: The PRACTIS guide. Int. J. Behav. Nut. Phys. Act. 2018, 15, 51. [CrossRef] [PubMed]

15. Moore, G.F.; Audrey, S.; Barker, M.; Bond, L.; Bonell, C.; Hardeman, W.; Moore, L.; O'Cathain, A.; Tinati, T.; Wight, D.; et al. Process evaluation of complex interventions: Medical Research Council guidance. BMJ 2015, 350. [CrossRef] [PubMed]

16. Bonell, C.; Fletcher, A.; Morton, M.; Lorenc, T.; Moore, L. Realist randomised controlled trials: A new approach to evaluating complex public health interventions. Soc. Sci. Med. 2012, 75, 2299-2306. [CrossRef] [PubMed]

17. Pawson, R.; Tilley, N.; Tilley, N. Realistic Evaluation; Sage: London, UK, 1997.

18. Bendassolli, P.F. Theory Building in Qualitative Research: Reconsidering the Problem of Induction. Forum Qual. Soc. Res. 2013, 14. [CrossRef]

19. Wong, G.; Greenhalgh, T.; Westhorp, G.; Pawson, R. Realist methods in medical education research: What are they and what can they contribute? Med. Educ. 2012, 46, 89-96. [CrossRef] [PubMed]

20. Moser, C. Gender Planning and Development: Theory, Practice and Training; Routledge: London, UK, 1993.

21. Craig, P.; Dieppe, P.; Macintyre, S.; Michie, S.; Nazareth, I.; Petticrew, M.J.B. Developing and evaluating complex interventions: The new Medical Research Council guidance. BMJ 2008, 337, a1655. [CrossRef]

22. FHI 360. Gender Intergration Framework: How to Integrate Gender in Every Aspect of Our Work; FHI 360: Durham, NC, USA, 2012.

23. Tong, A.; Craig, J.; Sainsbury, P. Consolidated criteria for reporting qualitative research (COREQ): A 32-item checklist for interviews and focus groups. Int. J. Qual. Health Care 2007, 19, 349-357. [CrossRef] [PubMed]

24. Milena, Z.R.; Dainora, G.; Alin, S. Qualitative research methods: A comparison between focus-group and in-depth interview. Ann. Univ. Oradea Econ. Sci. Ser. 2008, 17, 1279-1283. 
25. Saunders, B.; Sim, J.; Kingstone, T.; Baker, S.; Waterfield, J.; Bartlam, B.; Burroughs, H.; Jinks, C. Saturation in qualitative research: Exploring its conceptualization and operationalization. Qual. Quant. 2018, 52, 1893-1907. [CrossRef] [PubMed]

26. McMahon, S.A.; Winch, P.J. Systematic debriefing after qualitative encounters: An essential analysis step in applied qualitative research. BMJ Glob. Health 2018, 3, e000837. [CrossRef] [PubMed]

27. Czarniawska-Joerges, B. Shadowing: and Other Techniques for Doing Fieldwork in Modern Societies; Liber/Copenhagen Business School Press DK: Malmö, Sweden, 2007.

28. Saunders, R.P.; Evans, M.H.; Joshi, P. Developing a Process-Evaluation Plan for Assessing Health Promotion Program Implementation: A How-To Guide. Health Promot. Pract. 2005, 6, 134-147. [CrossRef] [PubMed]

29. Steckler, A.B.; Linnan, L.; Israel, B. Process Evaluation for Public Health Interventions and Research; Jossey-Bass: San Francisco, CA, USA, 2002.

30. UNICEF. Briefing Note: Enhanced Programming and Results through Monitoring Results for Equity Systems (MoRES); UNICEF: New York, NY, USA, 2013.

31. IBM Corp. IBM SPSS Statistics for Windows; IBM Corp: Armonk, NY, USA, 2017.

32. QSR International Pty Ltd. NVivo Qualitative data Analysis Software; QSR International: Melbourne, Australia, 2018.

33. Brannen, J. Mixing Methods: Qualitative and Quantitative Research; Routledge: London, UK, 1992.

34. The National Health and Medical Research Council; The Australian Research Council; Universities Australia. National Statement on Ethical Conduct in Human Research 2007 (Updated 2018); National Health and Medical Research Council: Canberra, Australia, 2018.

35. Esposito, N. From Meaning to Meaning: The Influence of Translation Techniques on Non-English Focus Group Research. Qual. Health Res. 2001, 11, 568-579. [CrossRef] [PubMed]

36. Regmi, K.; Naidoo, J.; Pilkington, P. Understanding the Processes of Translation and Transliteration in Qualitative Research. Int. J. Qual. Methods 2010, 9, 16-26. [CrossRef] 